\title{
Is Pharmaceutical Detailing Informative? Evidence from Contraindicated Drug Prescriptions*
}

\author{
Guofang Huang \\ Purdue University
}

\author{
Matthew Shum \\ Caltech
}

Feb 25, 2018

\author{
Wei Tan \\ Compass Lexecon
}

\begin{abstract}
Crestor, an important but controversial cholesterol-lowering drug, is contraindicated for use by senior and Asian patients. In this paper, we exploit this fact along with a unique physician-level prescription and detailing data for statin drugs to examine the hypothesis of informative detailing. Our tests are based on a simple model in which detailing impacts physicians' expected match utility of Crestor for different types of patients. We find strong evidence for the informative-detailing hypothesis: relative to the other patients, detailing significantly reduces physicians' likelihood of prescribing Crestor to contraindicated patients. Our results are robust to detailing being correlated with physician-specific unobserved factors and/or differential trends in individual physicians' attitude towards Crestor.
\end{abstract}

Key Words: Pharmaceutical detailing, Informative advertising, Sales force, Contraindications, Bayesian learning models

*Corresponding author: Guofang Huang, email: huan1259@purdue.edu. We thank Daniel Sgroi, Brad Shapiro, Michelle Sovinsky and Juanjuan Zhang for comments on previous drafts. 


\section{Introduction}

Pharmaceutical companies spend tremendous resources to promote their drugs. For example, in 2003, the U.S. pharmaceutical industry spent around $\$ 6$ billion on "detailing" (Schweitzer (2007, pg. 85)): drug-company representatives' promotional visits to physicians' offices and hospitals. The huge promotional expenditures in pharmaceutical markets is a cause of concern, especially given the asymmetric information characterizing the drug prescription relationship between physicians and patients, and the potential for drug companies to sway physicians to prescribe drugs that may not be in patients' best interests.

In this paper, we explore the nature of these promotional office visits. In particular, we focus on detailing related to a particular cholesterol-lowering drug, Astra-Zeneca's Crestor (active ingredient rosuvastatin), during a period following its introduction to the market. Crestor's launch in late 2003 was accompanied by a huge marketing campaign. While this is typical for many new drugs, Crestor's case is noteworthy because, apparently, its marketing push was deemed sufficiently excessive - relative to Crestor's perceived therapeutic benefits - to warrant a highly critical editorial in The Lancet, the flagship British medical journal:

AstraZeneca's tactics in marketing its cholesterol-lowering drug, rosuvastatin, raise disturbing questions about how drugs enter clinical practice and what measures exist to protect patients from inadequately investigated medicines. ${ }^{1}$

Given the controversy surrounding Crestor's marketing campaign and the policy concerns arising from the potential agency conflicts between physicians and patients, it is interesting to look for evidence of detailing's benefits vis-a-vis this drug. Our investigation exploits a unique dataset containing records of detailing visits and prescriptions of cholesterol-lowering statin drugs at the individual physician level. This dataset, as well as medical features of the pharmaceutical prescription process, allow us to assess whether Crestor's detailing plays a beneficial role of providing information to physicians.

In our analysis, we exploit the contraindications indicated for Crestor. The basic intuition underlying our tests is straightforward. Suppose that detailing provides physi-

\footnotetext{
${ }^{1}$ From The Lancet (2003).
} 
cians with contraindication information for which they had no prior knowledge, and that detailing otherwise has no impact on physicians' prescription decisions. Then, detailing should make physicians less likely to prescribe the drug to the contraindicated patients. For Crestor, senior patients and patients of Asian descent are specifically contraindicated. So, under the above (very restrictive) assumptions, an intuitive test of informative detailing is to see whether physicians who have been detailed prescribe Crestor less often to these two types of patients than do physicians who have not been detailed. Our formal tests for informative detailing follow the intuitive idea but allow for, among other complicating factors: 1) that physicians, on average, may have some prior (mis)knowledge about the contraindications, and 2) that detailing may have a direct impact on physicians' general willingness to prescribe Crestor (besides the effect of providing the contraindication information).

We find strong evidence for the informativeness of detailing. Our tests strongly reject the null hypothesis of detailing being uninformative or purely persuasive. Our results are robust to the possibility of detailing being correlated with unobserved factors such as physicians' characteristics and/or their evolving attitude toward Crestor. Finally, to check the face validity of our test strategy, we perform "placebo tests" on some noncontraindicated patient groups. For these cases, we do not find similar patterns in our analysis, confirming the soundness of the basic idea underlying our tests.

The rest of the paper is organized as follows. Section 2 surveys the literature on testing the informativeness of advertising (broadly defined). Section 3 presents our empirical model and our tests. Section 4 contains a short description of the market for the statin class of cholesterol-lowering drugs and the patient types contraindicated for Crestor, according to the Food and Drug Administration's recommendations. It also introduces the data used in our analysis. Section 5 presents the estimation and test results. Section 6 concludes.

\section{Literature}

Even though detailing is traditionally regarded as sales instead of advertising, it may also be viewed as a form of advertising in a broad sense. In this section, we relate our paper to the broader literature on the possible informative effects of advertising. The 
advertising literature has drawn a distinction between the informative and persuasive effects of advertising. Informative advertising informs consumers about the prices and characteristics of the available products, while persuasive advertising is modeled as advertising that simply raises their willingness-to-pay for the advertised product. Wellknown theoretical treatments of persuasive advertising include Dixit and Norman's (1978) provocative paper on the welfare effects of advertising, while Butters (1977) and Grossman and Shapiro (1984) provide models of purely informative advertising. See Bagwell (2007) for a thorough survey of the literature.

However, the signaling models of advertising (cf. Nelson (1974), Kihlstrom and Riordan (1984), Milgrom and Roberts (1986)) point out that, in vertically-differentiated (i.e., quality-differentiated) product markets in which consumers are ill-informed regarding the relative qualities of the competing products, the effects of persuasive and informative advertising can be observationally equivalent. This is because in separating equilibria of these models, only high-quality firms undertake advertising, so that advertising is strictly informative regarding quality differences between competing products. Therefore, if product quality enters consumers' utility functions, advertising informs consumers that it is high-quality, and thus raises their willingness-to-pay, just as in the case of persuasive advertising.

This potential observational equivalence between persuasive and informative advertising makes it difficult to empirically test between them. The existing empirical work has addressed this question in both reduced-form and structural fashion. One important example of the reduced-form approach is Ackerberg (2001), which overcomes the observational equivalence problem by focusing on a market for a new good (a new brand of yogurt). By investigating whether advertising has a larger effect on consumers who have tried the new brand or on those who have not, it is able to distinguish between persuasive and informative advertising.

Examples of the structural approach to this question include Erdem and Keane (1996), Ackerberg (2003), and Anand and Shachar (2011). ${ }^{2}$ These papers consider a Bayesian-learning model, where consumers who are uninformed about the quality of a product learn about it through advertising. In this structural approach, the distinction between persuasive and informative advertising is modeled parametrically: persuasive

\footnotetext{
${ }^{2}$ See also Chan and Hamilton (2006) for a similar approach to patient learning in drug trials.
} 
advertising enters consumers' utility functions directly, while informative advertising provides a signal that allows consumers to updates their beliefs regarding product quality.

While our approach is more reduced-form, the starting point of our analysis is closest to Anand and Shachar's (2011) paper. Particularly, like Anand and Shachar (2011) and unlike Ackerberg (2001) (and the signaling literature), our paper focuses on advertising's role in horizontally-differentiated product markets, where the relative qualities of the competing products vary across consumers. In horizontally-differentiated markets, persuasive and informative advertising are no longer observationally equivalent: while persuasive advertising would still encourage higher usage across all consumers, informative advertising would encourage higher usage only by those consumers for which the advertised products is a good match. For consumers who are ill-matched to the product, strictly informative advertising should actually discourage use. Anand and Shachar (2011), in the context of a structural model of TV program choice, uses this insight to examine the role of advertising on television viewers' choice of programs to watch. Here, our paper uses a similar intuition to assess whether advertising has informative effects, by examining whether advertising increases or decreases physicians' probabilities of prescribing Crestor to contraindicated patients, relative to their other patients, after controlling for advertising's general positive impact for all patients.

This paper also utilizes a unique dataset containing information on prescription and exposure to detailing at the individual physician level. In particular, the availability of physician-level advertising exposure information distinguishes our paper from most others that focus on the pharmaceutical prescription process (Stern (1996), Ellison, Cockburn, Griliches, and Hausman (1997), Coscelli and Shum (2004), Crawford and Shum (2005), Ching (2010), Ching and Ishihara (2012), Ching, Clark, Horstmann, and Lim (2015)). For example, Ching and Ishihara (2012) measures the persuasive and informative effects of detailing using aggregate data of market shares and the detailing of an angiotensin-converting enzyme inhibitor from Canada. It identifies detailing's persuasive effect as its impact on the market shares of drugs with the same chemicals but different brands, and the informative effect as detailing's impact on the market shares of different chemicals. Ching, Clark, Horstmann, and Lim (2015) studies the effect of publicity and its interaction with detailing on demand for statin drugs, using 
data on monthly prescription and detailing at the product level.

Narayanan and Manchanda (2009) and Shapiro (2017) utilizes data from the same source as this paper does, but on different drug markets. Narayanan and Manchanda (2009) focuses on estimating a Bayesian learning model with physician-specific learning parameters to accommodate physicians' heterogeneous learning rates. Shapiro (2017) estimates the impact of detailing on off-label prescriptions. It finds that detailing slightly shifts prescriptions from off-label to on-label, consistent with our finding of detailing containing information about contraindications. Chintagunta, Jiang, and Jin (2009) incorporates adverse news events into their learning model of prescriptions in the Cox-2 Inhibitors market, but the role of detailing is not the main focus of their paper.

\section{Empirical Model and Tests}

Our tests of the informativeness of detailing are based on examining the relationship between detailing and contraindicated drug prescriptions. We start by setting up a simple econometric framework to relate Crestor prescription decisions to detailing and other factors.

Let us assume that there are two types of patients: the contraindicated patients and non-contraindicated patients. Let subscript $a$ denote the contraindicated type; subscript $n a$ denote the non-contraindicated type; $A_{t}$ be an indicator variable for a period- $t$ patient being the contraindicated type; and $d_{t}$ be a binary variable that indicates whether a physician is being detailed in period $t$. Let $\mu_{a, t}\left(\mu_{n a, t}\right)$ denote a physician's expected match utility from Crestor for a contraindicated (non-contraindicated) patient in pe$\operatorname{riod} t$, and $\mu_{t}$ denote the physician's expected match utility from Crestor for a general period- $t$ patient. For the simplicity of notation, we omit the subscript for physicians.

Now assume that the utility of prescribing Crestor to a period $t$ patient can be measured by the following indirect utility function:

$$
U_{t}^{*}=h\left(Z_{t}, \mu_{t}\right)+\varepsilon_{t},
$$

where $Z_{t}$ is a vector of patient characteristics; $\varepsilon_{t}$ is a scaler random shock that captures other unobserved factors affecting the prescription behavior.

The utility of not prescribing Crestor is normalized to zero. Then, the physician will prescribe Crestor if and only if $U_{t}^{*}$ exceeds zero. In the estimation, we assume 
that physicians are risk-neutral and that $h\left(Z_{t}, \mu_{t}\right)$ is a linear function of its arguments. Furthermore, we assume that $\varepsilon_{t}$ has such a distribution that there is the following linear probability model for Crestor prescription:

$$
\operatorname{Pr}\left(y_{t}=1\right)=\mu_{t}+Z_{t} \alpha,
$$

where $y_{t}$ equals one if the physician prescribes Crestor for a patient and zero otherwise. The linear probability model allows us to control for a rich set of fixed effects in the estimation.

To capture the impact of detailing on each type of patient, we assume the following transition process for $\mu_{m, t}$ :

$$
\mu_{m, t}=\mu_{m, t-1}+\theta_{m, t} d_{t},
$$

where $m \in\{a, n a\}$, and $\theta_{m, t}$ measures the impact of the detailing in period $t$ on the physician's expected match utility of Crestor for type- $m$ of patients. Intuitively, informative detailing requires that $\theta_{a, t}<\theta_{n a, t}$. Substituting expressions in (2) for $\mu_{a, t}$ and $\mu_{n a, t}$ in $\mu_{t}=A_{t} \mu_{a, t}+\left(1-A_{t}\right) \mu_{n a, t}$, we have:

$$
\mu_{t}=\mu_{n a, t-1}+\left(\mu_{a, t-1}-\mu_{n a, t-1}\right) A_{t}+\theta_{n a, t} d_{t}+\left(\theta_{a, t}-\theta_{n a, t}\right) A_{t} d_{t},
$$

Meanwhile, we can also express $\mu_{t-1}$ as follows:

$$
\mu_{t-1}=\mu_{n a, t-1}+\left(\mu_{a, t-1}-\mu_{n a, t-1}\right) A_{t-1}
$$

Substituting in the above expressions for $\mu_{t}$ and $\mu_{t-1}$ in (1), we get the following Crestor prescription probability model for period $t$ and period $t-1$, repsectively:

$$
\begin{gathered}
\operatorname{Pr}\left(y_{t}=1\right)=\beta_{t 0}+\beta_{t 1} A_{t}+\beta_{t 2} d_{t}+\beta_{t 3} A_{t} d_{t}+Z_{t} \alpha, \\
\operatorname{Pr}\left(y_{t-1}=1\right)=\beta_{t 0}+\beta_{t 1} A_{t-1}+Z_{t-1} \alpha,
\end{gathered}
$$

where $\beta_{t 1} \equiv \mu_{a, t-1}-\mu_{n a, t-1}, \beta_{t 2} \equiv \theta_{n a, t}$ and $\beta_{t 3} \equiv \theta_{a, t}-\theta_{n a, t}$. The model in (4) above applies to the periods before the first Crestor detailing visit to the physician.

The above equations suggest that the test against $H_{0}: \beta_{t 3} \geq 0$ makes an intuitive (and necessary) test of informative detailing. Our empirical work in this paper focuses on testing this hypothesis and examining its robustness across various subsamples of our dataset. 
Another practical issue regarding the test is that, ideally, we want to focus on the period around the visit at which a detailer may inform a physician about the contraindications. This is because once a physician is informed about the contraindications during a detailing visit, future detailing should no longer be informative regarding the issue. For this reason, we treat our data for each physician as consisting of (at most) two periods: before and after Crestor's first detailing visit to each physician. ${ }^{3}$ With this approach, the "After" period covers the informative detailing visit to each physician if one exits, and we can also drop the subscript " $t$ " for the $\beta$ parameters.

It is worth noting here that the test suggested above represents a very minimum requirement for informative detailing. The analysis in this paper does not touch on whether detailing provides objective information for all or most relevant information for physicians to make sound prescription decisions.

\section{Crestor and the Statin Drug Market}

In order to implement our test of the informativeness of detailing using data on Crestor detailing and prescriptions, we need to identify the contraindicated patient types for the drug. In this section, we first briefly describe the market for the statin class of cholesterol-lowering drugs (of which Crestor is a member) and then proceed to a more detailed discussion of the United States Food and Drug Administration's (FDA) recommendations for Crestor, which we use to pin down contraindicated patient types.

Worldwide, the statin class of cholesterol-lowering drugs constitutes the largest drug market, in terms of both sales and prescriptions. Statin drugs were introduced in the mid-1990s, and gained popularity quickly because they led to rapid and dramatic reductions of blood cholesterol levels in patients. Statins work mainly in the liver by inhibiting the enzyme HMG-CoA reductase, which triggers increased absorption of lowdensity lipoprotein (LDL, also known as "bad cholesterol") from the bloodstream and eventual clearance through the kidneys.

Besides Astra-Zeneca's Crestor, which was introduced in September 2003, the two other major statin drugs during our sample period were: Pfizer's Lipitor (atorvastatin),

\footnotetext{
${ }^{3}$ There is only the before period for physicians who had not been detailed by the end of the two years that our data cover.
} 
introduced in 1996, and Merck's Zocor (simvastatin), introduced in $1991 .{ }^{4}$ Because all statin drugs impose some strain on the liver and kidneys, they are contraindicated for patients who have liver or kidney damage.

However, because Crestor was a very powerful drug, there were some extra precautions for Crestor. In particular, the FDA label for Crestor, which appeared in its first form on August 12, 2003, contained a warning regarding patients of Asian descent, who appeared in clinical studies to retain much higher levels of drug concentration in their blood, relative to Caucasian users:

Pharmacokinetic studies show an approximate 2-fold elevation in median exposure in Japanese subjects residing in Japan and in Chinese subjects residing in Singapore when compared with Caucasians residing in North America and Europe. No studies directly examining Asian ethnic population residing in the U.S. are available, so the contribution of environmental and genetic factors to the observed increase in rosuvastatin drug levels have not been determined.

In the March 2, 2005 version of the FDA label, this precaution was strengthened, on the basis of studies on U.S. subjects:

Pharmacokinetic studies, including one conducted in the US, have demonstrated an approximate 2-fold elevation in median exposure in Asian subjects when compared with the Caucasian control group.

Furthermore, there is a another warning regarding prescribing Crestor to senior patients (over age 65), as these patients are more likely to develop myopathy (muscle pain and weakness), ${ }^{5}$ severe cases of which have resulted in death in patients taking Crestor:

Rovustatin should be prescribed with caution in patients with disposing factors for myopathy, such as renal impairment, advanced age, and hypothyroidism.

\footnotetext{
${ }^{4}$ Zocor lost patent protection in 2006 , and its active ingredient simvastatin is now available in generic versions.

${ }^{5}$ See the warning on patients disposed for myopathy in FDA's approval package from Aug 2003.
} 
Based on the FDA labels, we define senior patients and patients of Asian descent as the contraindicated patient types for Crestor in this paper. (For convenience, we will refer to patients of Asian descent as simply "Asian patients.") The warning regarding these patients is specific to Crestor and is not present for the other statin drugs. Though patients with myopathy are also warned about some other statin drugs, senior ("advanced-age") patients are specifically warned only about Crestor. If other statin drugs were also contraindicated for senior patients, how informative detailing would be reflected in Crestor prescription probabilities would be ambiguous.

\subsection{Data}

We use a panel dataset comprising prescriptions of statin drugs from a sample of 2400 U.S. physicians. ${ }^{6}$ The dataset is unique in that, for each physician, we observe a sample of prescriptions written between January 1, 2003 and December 31, 2004, as well as some characteristics of the patients. The observed patient characteristics allow us to identify the contraindicated patients. In addition, we also have a record of all the detailing visits made by pharmaceutical sales representatives during the same period. We construct our data by combining the prescription data and detailing data. Thus, each observation in our sample is a prescription for which we observe the patient's characteristics, the prescription made by the physician and measures of detailing activity at the physician's office. We use the data from Crestor's approval date, Aug 13, 2003, to the end of 2004 in all of our analysis.

Tables 1 and 2 show the description and the summary statistics of the variables included in our analysis. The dependent variables are "Crestor (any dosage)" and "High-dosage Crestor," which are dummy variables that indicate whether Crestor and high-dosage (20mg or 40mg) Crestor were prescribed, respectively. ${ }^{7}$ Both dependent variables are relevant for our purpose because physicians who are informed about the

\footnotetext{
${ }^{6}$ The data are obtained from a pharmaceutical consulting firm, which also provided a similar dataset to a marketing study by Narayanan and Manchanda (2009). The data include more physicians with higher prescription volumes relative to the whole U.S. population of physicians. As will become clear later, the oversampling of high-volume prescribers makes it harder to detect informative detailing.

${ }^{7}$ There are four dosage forms for Crestor: $5 \mathrm{mg}, 10 \mathrm{mg}, 20 \mathrm{mg}$ and $40 \mathrm{mg}$. $5 \mathrm{mg}$ are considered low dosage, $10 \mathrm{mg}$ normal dosage and the $20 \mathrm{mg}$ and $40 \mathrm{mg}$ high dosages.
} 
contraindications may react by either being more cautious about prescribing Crestor to the contraindicated patients in general or by just trying to avoid prescribing the high-dosage versions to them. (High-dosage) Crestor was prescribed (1.3\%) $9.3 \%$ of the time in our data period.

The first set of explanatory variables used in the regression analysis includes measures of detailing activities at the physician's office. The dummy variable "After" indicates whether a prescription was made after Crestor's first detailing visit to the physician. The date of Crestor's first detailing visit varies significantly across physicians. For the 2,400 physicians in our sample, Crestor made the first detailing visit within the first month of its approval date to $35 \%$ of them, and had not made the first detailing visit to $23 \%$ of them by the end of 2004 . Of all the prescriptions in our sample, $86.6 \%$ are made after physicians received their first detailing visits from Crestor.

"Competitors' detailing" is defined as the average total number of detailing visits to a physician per day, from Crestor's approval date until a prescription date, made by Crestor's competitors. The variable measures competitors' detailing intensity at each physician before a prescription date. The average Competitors' detailing is 0.145 visits per day since Crestor's approval.

The second set of variables we control for are a number of patient characteristics, including gender, age, race, diagnosis types (new or ongoing), severity (mild, moderate or severe), prescription types (new or renewal), and payment methods (Cash/Indemnity, Medicaid, Medicare, HMO/PPO/POS). About 53 percent of visits are made by male patients, and 44 percent are made by senior patients who are 65 or older. Asian and Hispanic patients account for 2.4 percent and 5.6 percent, respectively, of all the patient visits. Seventy-seven percent are considered to have moderate conditions, six percent severe conditions, and the rest mild conditions. Nine percent of the cases are from a new diagnosis. Patients differ in their payment method as well: 51 percent are covered by $\mathrm{HMO} / \mathrm{PPO} / \mathrm{POS}$; two percent and 39 percent of patients are covered by Medicaid and Medicare respectively; and remaining payment types are either cash or indemnity. 


\section{$5 \quad$ Empirical Results}

Before discussing the estimation and test results, we first look at some patterns from the raw data. Table 3 shows the prescriptions by drug and patient type, and Table 4 shows the shares of each dosage by patient types in cases in which Crestor is prescribed. As expected, senior and Asian patients are less likely to be prescribed Crestor: senior and Asian patients are prescribed Crestor 7.1 percent and 7.8 percent of the time respectively, while the other patients are prescribed Crestor 11.1 percent of the time. Furthermore, relative to the other patients, senior and Asian patients are less likely to be prescribed the $20 \mathrm{mg}$ or $40 \mathrm{mg}$ dosages if Crestor is prescribed for them. These numbers indicate that, on average, physicians have, to some extent, become aware of the contraindications of Crestor for senior and Asian patients by the end of our data period. The question, then, is whether detailing constitutes a source of such information.

\subsection{Baseline Empirical Results}

\subsubsection{Linear probability model of Crestor prescription}

The estimation results of the linear probability model of Crestor prescription (1) are reported in column one in Table 5. The dummies of Year*Month, which help control for the time trend in the average willingness to prescribe Crestor, are included in the model but omitted from the table to save space. Our estimates are strikingly clear. First, the coefficient of "After" is significantly positive, showing that detailing significantly increases the prescription probability for patients for whom Crestor is not contraindicated.

In addition, the overall effect of detailing for senior patients and Asian patients is also positive and statistically significant at the $1 \%$ and $10 \%$ levels respectively. ${ }^{8}$ This is consistent with findings in the literature using similar data and suggests that detailing is, above all, an effective marketing tool. However, we are unable to conclude whether detailing has a persuasive nature, because we cannot infer whether the detailing exaggerated the true match utilities of Crestor.

\footnotetext{
${ }^{8}$ The overall impact of detailing on the prescription of Crestor to senior and Asian patients is measured by the sum of the coefficients of "After" and "After*Senior" and the sum of the coefficients of "After" and "After*Asian" respectively.
} 
Furthermore, for the coefficients of senior and Asian patient indicators (i.e., $\beta_{t 1}$ in our empirical model), the former, but not the latter, is significantly negative, meaning that senior patients are indeed less likely to be prescribed Crestor. This suggests that, on average, physicians have some prior knowledge about the contraindication for senior patients before being detailed.

More importantly, the coefficients of the interaction terms of "After*Senior" and "After*Asian" (i.e., corresponding to $\beta_{t 3}$ in our empirical model) are also significantly negative, meaning that the prescription probability of Crestor for the contraindicated patients decreases relative to the other patients after the first detailing visit to each physician. This suggests that detailing is, indeed, informative about contraindication, as opposed to being a completely indiscriminate marketing tool. ${ }^{9}$

Lastly, the estimates of other coefficients seem reasonable. Patients with moderate and severe symptoms are more likely to be prescribed Crestor, which is consistent with Crestor's exceptional power in lowering cholesterol levels. Physicians are also more likely to prescribe Crestor in new prescriptions (relative to as renewals of previous prescriptions) and for treating new diagnoses. The former finding is probably driven by the simple fact that Crestor was newly introduced to the market, while the latter suggests that, relative to existing diagnoses, physicians are more likely to try Crestor when treating new diagnoses. The impact of competitors' detailing is negative but statistically insignificant. The negative impact shows the competition effect of other companies' detailing, and the statistical insignificance could be partly due to the fact that the competing statin drugs have been on the market for a few years, so additional detailing has only a small marginal effect.

\footnotetext{
${ }^{9}$ There can be Hawthorne effects, simply because the panel of physicians in our data report information on their prescriptions and detailing to our data provider. However, with our focus on the interaction effects of detailing and contraindications (as opposed to the main effect of detailing), the Hawthorne effect seems unlikely to be the driver of our findings. In addition, pharmaceutical companies regularly observe physicians' prescriptions through data obtained from 'Health Information Organizations'. As a result, physicians have always been under observation and, thus, are less likely subject to Hawthorne effects.
} 


\subsubsection{Linear probability model of the high-dosage Crestor prescrip- tion}

Column two in Table 5 shows the estimation results of the linear probability model of the high-dosage Crestor prescription. Focusing on high-dosage Crestor prescriptions yields a few interesting findings. First, similarly, we find that detailing has a significantly positive impact on the prescription of high-dosage Crestor to non-contraindicated patients. However, the detailing's overall impact on the prescription of high-dosage Crestor to senior (Asian) patients is negative (positive) but statistically insignificant. These results are in contrast to detailing's overall significant positive impact on the prescription of Crestor to senior and Asian patients, and they are consistent with Crestor being cautious in marketing its high-dosage forms to senior and Asian patients.

In addition, the results lend further support to the informativeness of Crestor's detailing. In particular, the estimated coefficients of the interaction terms of "After*Senior" and "After*Asian" are significantly negative, as in the linear probability model of Crestor prescription.

\subsubsection{Linear probability model with a more flexible specification for the effect of detailing on senior Asian patients}

The specifications in columns one and two in Table 5 are, a priori, restrictive for the effect of detailing on senior Asian patients. ${ }^{10}$ In particular, the specifications do not include the interaction terms of "Senior*Asian" and "After*Senior*Asian," ${ }^{*}$ which implies that the effect of detailing on senior Asian patients, relative to the main effect captured by the coefficient of "After," is simply the sum of the coefficients of "After*Senior" and "After*Asian."

To investigate the impact of the simplifying restriction, we estimate the linear prescription probability models with the additional interaction terms and report the results in columns three and four in Table 5. The estimates show that, for the prescriptions of Crestor (of any dosage) and high-dosage Crestor, neither of the two additional interaction terms is significant at any conventional levels, and the rest of the estimates in the

\footnotetext{
${ }^{10}$ Note that we refer to senior patients of Asian descent as "senior Asian patients" in this paper.

${ }^{11}$ We thank one of the referees for pointing out the issue.
} 
more flexible specifications are very close to the corresponding estimates in columns one and two. The two additional interaction terms are also insignificant when we include the fixed effects of physicians or physician*Year*Month (which we explore later). We note, however, that there are only a small number of observations of senior Asian patients in our data, which could (partly) explain our findings. Therefore, we note only that we find no evidence of the effect of detailing on senior Asian patients being significantly different from that implied by our original estimates (in columns one and two in Table 5), and we focus on the average effect of detailing on senior patients and Asian patients separately for the rest of the paper.

In what follows, we first check the robustness of our results against the possibility of detailing being endogenous and against the heterogeneity in the effect of detailing. We then demonstrate the face validity of our test strategy by applying similar tests to other non-contraindicated patient types.

\subsection{Endogenous Detailing}

Detailing might be endogenous, for example, due to targeted marketing and omitted control variables. For evidence of correlation between detailing and physician-level information, Table 6 presents the results of linear regressions of three physician-level detailing variables on "TotalRx," the total number of statin prescriptions made per physician from the start of 2003 until Aug 12, 2003 (the day before Crestor's approval). The three detailing variables are: Detailed (a binary variable indicating whether a physician had been detailed by Crestor by the end of 2004); Delay (the number of days from Crestor's approval on Aug 13, 2003 until the first detailing visit by Crestor to a physician); and Average competitors' detailing (the average competitors' detailing intensity at each physician after Aug 13, 2003). The total number of statin prescriptions per physician varies from zero to 591 and has a mean of 41 , showing significant heterogeneity in each physician's relevance for Crestor. The regression results show that physicians with higher statin prescription volumes 1) are more likely to have been detailed by Crestor by the end 2004; 2) are detailed earlier by Crestor; and 3) are more frequently detailed by the competing companies.

We take the panel-data fixed-effect approach to deal with the potential endogeneity 
in the companies' detailing activities. ${ }^{12}$ In particular, we re-estimate the linear probability models for Crestor and high-dosage Crestor prescriptions to allow for the physician fixed effects. The fixed effects help control for such factors as physicians' prescription volumes and their willingness to prescribe new drugs. The results of the fixed-effect regressions are presented in columns one and two in Table 7. The coefficient estimates are in general similar to those reported for the models without the physician fixed effects. Importantly, the estimated coefficients of the interaction terms ("After*Senior" and "After*Asian") are all negative, with magnitude and statistical significance similar to those reported in Table 5. Thus, the estimates of these coefficients of main interest to us are robust to controlling for physician fixed effects.

Meanwhile, a few coefficients have noticeably different point estimates after controlling for physician fixed effects: 1) the coefficients of "After" are positive but smaller and statistically less significant; 2) the coefficients of Competitors' detailing are negative, larger in magnitude and statistically more significant; and 3) the coefficients of Senior patient indicators turn out to be positive and statistically insignificant. The direction of corrections in the coefficients of the detailing variables ("After" and "Competitors' detailing") show that omitting the physician fixed effects leads to an overestimation of the effect of Crestor's detailing and an underestimation of the competition effect of the other companies' detailing. This pattern is consistent with Crestor and its competitors targeting their detailing effort at physicians with higher willingness to prescribe Crestor. The fact that the coefficients of the senior patient indicator become insignificant after controlling for the physician fixed effects suggests that physicians' willingness to prescribe Crestor is related to how often they treat senior patients. Overall, these results confirm the robustness of our main findings that Crestor's detailing signaled an inferior match quality of Crestor, especially the high-dosage forms, for the contraindicated patients relative to the other patients.

A potential concern about the above analysis is that the trend in the willingness

\footnotetext{
${ }^{12}$ The instrumental-variable (IV) approach could also be applied, in principle, to deal with the endogeneity problem here. For example, the one-year lagged competitors' detailing intensity on the same calendar day could be an IV for the current competitors' detailing intensity. We, however, cannot take the approach here because it would require data from 2002, which are not included in our data. In addition, it seems also challenging to find an instrument for the variable "After" within our data.
} 
to prescribe Crestor may be different across physicians (due, for example, to exposure to different sources of information) and, thus, cannot be fully controlled for by the dummy variables of Year*Month. Individual physicians' evolving attitude toward Crestor affects their prescription decisions and can also affect the competitors' detailing intensity and the timing of Crestor's first detailing visit to each physician. To address this concern, we re-estimate the linear probability models to allow for the fixed effects of physician*Year*Month. We report the estimation results in columns three and four in Table 7. Overall, adding the additional fixed effects has little impact on our estimates, and the qualitative results of all the tests remain the same. Therefore, we conclude that our finding of Crestor's detailing being informative is robust to physician-specific trends in the attitude toward Crestor.

Lastly, it is worth noting the limitations in our fixed-effect approach to dealing with the endogeneity in detailing. For example, our conclusion above would be wrong if the following hypothetical scenario were true. In particular, suppose that Crestor detailers somehow know when certain physicians are about to decrease their prescriptions to contraindicated patients. At that moment, they visit the physicians to prevent the decrease. However, the physicians are going to decrease such prescriptions in any case, and the detailers always fail to change their behavior. Then, with our fixed effects, we would still find that after the detailing visits, the physicians decrease prescriptions to the contraindicated patients. However, the detailers were actually trying to mislead, which is the opposite of our conclusion. Even though this kind of hypothetical scenario seems unlikely to us, readers should keep the caveat in mind when interpreting our results. Note also that our analysis depends mainly on the estimated effect of detailing on particular contraindicated patients relative to that on the other patients. This particular focus should make our results less sensitive to minor endogeneity problems in detailing.

\subsection{The Heterogeneity in the Effect of Detailing}

Previous studies (e.g., Narayanan and Manchanda (2009)) find that the effect of detailing varies significantly across physicians. It would be interesting to know whether and how the effect of detailing varies across physicians in our data, especially for the contraindicated patients. Here, we focus on analyzing how this effect varies across 
physicians by their prescription volumes for statins. For this purpose, we extend the prescription probability models by adding the interaction terms of "After*TotalRx," "After*Senior*TotalRx" and "After*Asian*TotalRx." We focus on the specifications with fixed effects and report the estimates in Table 8.

The estimates show interesting heterogeneity in the effect of detailing. First, while the coefficients of "After" are significantly positive in all four models, the coefficients of "After*TotalRx" are negative in all four models and statistically significant in all cases except for the one for high-dosage Crestor in the last column (with the fixed effects of Physician*Year*Month). These estimates show that, while the main effect of detailing on Crestor prescription is positive for most physicians, it is significantly weaker for physicians with larger prescription volumes. Second, the coefficients of "After*Senior" and "After*Asian" are again all significantly negative. Yet the coefficients of "After*Senior*TotalRx" and "After*Asian*TotalRx" are all positive (but statistically insignificant, with only the coefficients of "After*Senior*TotalRx" being significant at the $10 \%$ level). ${ }^{13}$ Intuitively, these estimates suggest that the informative effect of detailing for the contraindicated patients is significant but somewhat weaker for physicians with larger prescription volumes.

One possible explanation of the above findings is that physicians with higher prescription volumes simply are not paying as much attention to detailers due to their busier schedule and limited attention capacity. Another possible explanation is that physicians with higher prescription volumes are more knowledgeable about the efficacy and the contraindications of statin drugs (including Crestor) and, thus, are less likely to be affected by detailing. It would be interesting to distinguish between these different explanations. The task is, however, challenging for us due to data limitations and, thus, we leave them to future research.

\subsection{Validity Checks: Evidence from "Placebo Tests"}

The above tests of the informativeness of detailing are based on observable contraindicated groups of patients. The underlying argument is that if detailing were informative,

\footnotetext{
${ }^{13}$ As we noted earlier, our data include more physicians with higher prescription volumes relative to the whole U.S. population of physicians. The findings here also imply that the oversampling of high-volume prescribers makes it harder to detect informative detailing.
} 
we should be able to find that it signals the inferior match quality of Crestor for the contraindicated patients. In this subsection, we use placebo tests to check the face validity of our basic test idea. In these placebo tests, we show that the observed patterns of the coefficients in our analysis above disappear if we conduct the same tests on Crestor with patient groups that are not specifically contraindicated.

First, we look at the prescription of Crestor to male patients, who, as a group are not specifically contraindicated for Crestor. The estimates of the models, including dummy variables and interaction terms for male patients, are presented in Table 9. The first and second columns show the estimates of the baseline specification of the linear probability models for the prescription of Crestor and high-dosage Crestor; the specifications in columns three and four add the physician fixed effects; and the specifications in the last two columns add the fixed effects of physician*Year*Month.

The coefficient of the male indicator is significantly negative in all three specifications of the model for Crestor prescription, but it is not statistically significant in any specification of the model of high-dosage Crestor prescription. More importantly, the interaction term "After*Male" is not significant in either statistical or economic terms in any specification of the two models. Thus, although male patients are less likely prescribed Crestor for some reason, the pattern seems unrelated to Crestor's detailing; and gender is irrelevant to the prescription of high-dosage Crestor, unlike what we find for the contraindicated patients. Therefore, overall, the results show no evidence that detailing is signaling a different match quality of Crestor for male patients, as we would expect in this placebo test.

We further replicate the same exercise for Hispanic patients. The estimates of the models are presented in Table 10. The coefficients of the Hispanic patient indicator and the interaction term "After*Hispanic" is not significant in either statistical or economic terms in any specification of the two models. These results are consistent with the fact that Crestor is not specifically contraindicated for Hispanic patients.

To summarize this section, first, our test results presented strong evidence indicating that detailing actually is informative; second, the results are robust to the possibility of detailing being correlated with physician-specific unobserved factors; finally, the validity of our tests is supported by the results that we found by conducting similar tests for other irrelevant cases. 


\section{Concluding Remarks}

In this paper, we examined the potential beneficial role of pharmaceutical detailing in informing the prescription process. As profit-driven as detailing is, we find some strong evidence showing that it is also informative about the negative features of the drug being promoted. The Federal Food, Drug, and Cosmetic Act, which regulates pharmaceutical advertising and drug labeling in the United States, requires promotional statements to present "a fair balance between information relating to side effects and contraindications and information relating to effectiveness of the drug." The Act also requires that "the presentation of true information relating to side effects and contraindications is comparable in depth and detail with the claims for effectiveness or safety." ${ }^{14}$ Even though the documents/material left by detailers are legally treated as labels and, thus, are subject to the same regulation, oral promotional statements by detailers are currently not regulated. ${ }^{15}$ Our findings are thus important for the debate over potential regulation of the pharmaceutical industry's detailing activities.

In the meantime, our findings also raise the question of why self-interested pharmaceutical companies and sales representatives should actively reveal such negative information about their own drugs. The regulation on the print material that detailers provide creates some incentive for them to be informative. There can be more information on the efficacy and safety in the print material if it is balanced by sufficient information on side effects and contraindications. Reputation could be another mechanism that leads to informative detailing. Detailers want to inform doctors of the contraindications if doing so helps them maintain good relationships with doctors and/or helps build doctors' trust in them. Competition in the market can make such goodwill with doctors even more valuable, and detailers would also want to avoid the negative information being exploited by competitors to undermine their credibility. ${ }^{16}$ An empirical analysis of the mechanism(s) underlying detailers' "self-discipline" would further inform the controversy surrounding pharmaceutical marketing. However, an-

\footnotetext{
${ }^{14}$ Source: https://www.accessdata.fda.gov/scripts/cdrh/cfdocs/cfcfr/CFRSearch.cfm?fr=202.1, part (d)

(5) ii in Section 202.1 "Prescription-drug advertisements"

${ }^{15}$ This may partly explains the industry's increasing reliance on detailers for promotions.

${ }^{16}$ Related to this argument, Gentzkow and Shapiro (2006) shows that media companies, which care about the reputation of their news quality, are less biased when there is more competition.
} 
swers to such questions are beyond the scope of the current paper, and we leave them to our future research. 


\section{References}

AckerberG, D. (2001): "Empirically Distinguishing Informative and Prestige Effects of Advertising," RAND Journal of Economics, 32, 316-333.

(2003): "Advertising, Learning, and Consumer Choice in Experience Good Markets: A Structural Examination," International Economic Review, 44, 10071040.

Anand, B., And R. Shachar (2011): "Advertising, the matchmaker," The RAND Journal of Economics, 42(2), 205-245.

Bagwell, K. (2007): "The Economic Analysis of Advertising," in Handbook of Industrial Organization, Vol. 3, ed. by M. Armstrong, and R. Porter. North-Holland.

Butters, G. (1977): "Equilibrium Distributions of Sales and Advertising Prices," Review of Economic Studies, 44, 465-491.

Chan, T. Y., and B. H. Hamilton (2006): "Learning, Private Information, and the Economic Evaluation of Randomized Experiments," Journal of Political Economy, 114, 997-1040.

Ching, A. (2010): "A Dynamic Oligopoly Structural Model for the Prescription Drug Market After Patent Expiration," International Economic Review, 51, 1175-1207.

Ching, A. T., R. Clark, I. Horstmann, and H. Lim (2015): "The effects of publicity on demand: The case of anti-cholesterol drugs," Marketing Science, 35(1), $158-181$.

Ching, A. T., And M. Ishinara (2012): "Measuring the informative and persuasive roles of detailing on prescribing decisions," Management Science, 58(7), 1374-1387.

Chintagunta, P., R. Jiang, And G. Jin (2009): "Information, learning, and drug diffusion: The case of Cox-2 inhibitors," Quantitative Marketing and Economics, $7(4), 399-443$.

Coscelli, A., And M. Shum (2004): "An Empirical Model of Learning and Patient Spillovers in New Drug Entry," Journal of Econometrics, 122, 213-246.

Crawford, G., And M. Shum (2005): "Uncertainty and Learning in Pharmaceutical Demand," Econometrica, 73, 1137-1174. 
Dixit, A., And V. Norman (1978): "Advertising and Welfare," Bell Journal of Economics, pp. 1-19.

Ellison, S., I. Cockburn, Z. Griliches, and J. Hausman (1997): "Characteristics of Demand for Pharmaceutical Products: An Examination of four Cephalosporins," RAND Journal of Economics, 28, 426-446.

Erdem, T., and M. Keane (1996): "Decision-making Under Uncertainty: Capturing Dynamic Brand Choice Processes in Turbulent Consumer Goods Markets," Marketing Science, 15, 1-20.

Food And Drug Administration (2003, 2005): "Labels for Crestor," Available at http://www.fda.gov/cdei/foi/label/2003/21366_crestor_lbl.pdf.

Gentzkow, M., and J. M. Shapiro (2006): "Media bias and reputation," Journal of political Economy, 114(2), 280-316.

Grossman, G., And C. Shapiro (1984): "Informative Advertising with Differentiated Products," Review of Economic Studies, 51, 63-81.

Kinlstrom, R., And M. Riordan (1984): "Advertising as a Signal," Journal of Political Economy, 92, 427-450.

Milgrom, P., And J. Roberts (1986): "Price and Advertising Signals of Product Quality," Journal of Political Economy, 94, 796-821.

Narayanan, S., AND P. Manchanda (2009): "Heterogeneous Learning and the Targeting of Marketing Communication for New Products," Marketing Science, 28, 424441.

Nelson, P. (1974): "Advertising as Information," Journal of Political Economy, 82, $729-755$.

Schweitzer, S. O. (2007): Pharmaceutical economics and policy. Oxford University Press.

Shapiro, B. (2017): "Informational Shocks and the Effects of Physician Detailing," Discussion paper, Chicago Booth Working Paper.

Stern, S. (1996): "The Demand for Pharmaceuticals," Kellogg School, Manuscript. The Lancet (2003): "The statin wars: why AstraZeneca must retreat," Vol. 362, October 25. 


\section{Tables}

Table 1: Variable Descriptions

\begin{tabular}{|c|c|}
\hline Variable & Description \\
\hline Crestor (any dosage) & Indicator of Crestor (of any dosage) being prescribed \\
\hline High-dosage Crestor & Indicator of High-dosage (20mg or $40 \mathrm{mg}$ ) Crestor being prescribed \\
\hline Moderate & Indicator of moderate symptoms \\
\hline Severe & Indicator of severe symptoms \\
\hline New prescription & Indicator of a new prescription \\
\hline New diagnosis & Indicator of a new diagnosis \\
\hline Medicare & Indicator of a patient covered by Medicare \\
\hline Medicaid & Indicator of a patient covered by Medicaid \\
\hline $\mathrm{HMO} / \mathrm{PPO} / \mathrm{POS}$ & Indicator of a patient covered by a $\mathrm{HMO} / \mathrm{PPO} / \mathrm{POS}$ plan \\
\hline Competitors' detailing & The average total number of detailing visits per day by competitors \\
\hline Male & Indicator of a patient being male \\
\hline Senior & Indicator of a patient being older than 65 \\
\hline Asian & Indicator of a patient being of Asian descent \\
\hline Hispanic & Indicator of a patient being of Hispanic descent \\
\hline After & Indicator of a time after the first detailing visit by Crestor to a physician \\
\hline Senior*Asian & Interaction of Senior and Asian \\
\hline After*Senior & Interaction of After and Senior \\
\hline After*Asian & Interaction of After and Asian \\
\hline After*Hispanic & Interaction of After and Hispanic \\
\hline TotalRx & Total number of statin-class prescriptions per physician in 2003 before Crestor launch \\
\hline
\end{tabular}


Table 2: Summary Statistics

\begin{tabular}{|c|c|c|c|c|c|}
\hline Variable & Mean & Std. Dev. & Min. & Max. & $\mathbf{N}$ \\
\hline Crestor (any dosage) & 0.093 & 0.29 & 0 & 1 & 227282 \\
\hline High-dosage Crestor & 0.013 & 0.112 & 0 & 1 & 227282 \\
\hline Moderate & 0.773 & 0.419 & 0 & 1 & 227282 \\
\hline Severe & 0.064 & 0.245 & 0 & 1 & 227282 \\
\hline New prescription & 0.167 & 0.373 & 0 & 1 & 227282 \\
\hline New diagnosis & 0.089 & 0.285 & 0 & 1 & 227282 \\
\hline Medicare & 0.392 & 0.488 & 0 & 1 & 227282 \\
\hline Medicaid & 0.024 & 0.153 & 0 & 1 & 227282 \\
\hline $\mathrm{HMO} / \mathrm{PPO} / \mathrm{POS}$ & 0.511 & 0.5 & 0 & 1 & 227282 \\
\hline Competitors' detailing & 0.145 & 0.153 & 0 & 2.667 & 227282 \\
\hline Male & 0.533 & 0.499 & 0 & 1 & 227282 \\
\hline Senior & 0.444 & 0.497 & 0 & 1 & 227282 \\
\hline Asian & 0.024 & 0.153 & 0 & 1 & 227282 \\
\hline Senior Asian & 0.009 & 0.095 & 0 & 1 & 227282 \\
\hline Hispanic & 0.056 & 0.23 & 0 & 1 & 227282 \\
\hline After & 0.866 & 0.341 & 0 & 1 & 227282 \\
\hline After*Senior & 0.384 & 0.486 & 0 & 1 & 227282 \\
\hline After*Asian & 0.021 & 0.144 & 0 & 1 & 227282 \\
\hline After*Senior Asian & 0.008 & 0.09 & 0 & 1 & 227282 \\
\hline After*Hispanic & 0.049 & 0.217 & 0 & 1 & 227282 \\
\hline TotalRx & 0.107 & 0.112 & 0 & 0.591 & 227282 \\
\hline
\end{tabular}


Table 3: Prescription to Contraindicated Patients and Other Patients

\begin{tabular}{lcccccc}
\hline \hline & \multicolumn{2}{c}{ Senior Patients } & \multicolumn{2}{c}{ Asian Patients } & \multicolumn{2}{c}{ Other Patients } \\
Drugs & Frequency & Percentage & Frequency & Percentage & Frequency & Percentage \\
\hline Crestor & 7,032 & 7.12 & 428 & 7.83 & 13,618 & 11.07 \\
Other Drugs & 91,731 & 92.88 & 5,036 & 92.17 & 109,437 & 88.93 \\
\hline
\end{tabular}

Table 4: The Strength of Crestor Prescribed to Contraindicated Patients and Other Patients

\begin{tabular}{lccc}
\hline \hline Strength & $\begin{array}{c}\text { Senior Patients } \\
\text { Percentage }\end{array}$ & $\begin{array}{c}\text { Asian Patients } \\
\text { Percentage }\end{array}$ & $\begin{array}{c}\text { Other Patients } \\
\text { Percentage }\end{array}$ \\
\hline $5 \mathrm{mg}$ & 4.08 & 4.91 & 2.58 \\
$10 \mathrm{mg}$ & 82.82 & 85.51 & 83.22 \\
$20 \mathrm{mg}$ & 11.15 & 9.11 & 12.00 \\
$40 \mathrm{mg}$ & 1.95 & 0.47 & 2.20 \\
\hline
\end{tabular}


Table 5: Prescription of Crestor to Senior and Asian Patients: the Impact of Detailing

\begin{tabular}{|c|c|c|c|c|}
\hline & $\begin{array}{c}\text { Crestor (any } \\
\text { dosage) }\end{array}$ & $\begin{array}{c}\text { High-dosage } \\
\text { Crestor }\end{array}$ & $\begin{array}{c}\text { Crestor (any } \\
\text { dosage) }\end{array}$ & $\begin{array}{c}\text { High-dosage } \\
\text { Crestor }\end{array}$ \\
\hline Moderate & $\begin{array}{c}0.0335^{* * *} \\
(0.00464)\end{array}$ & $\begin{array}{c}0.00488^{* * *} \\
(0.000930)\end{array}$ & $\begin{array}{c}0.0335^{* * *} \\
(0.00464)\end{array}$ & $\begin{array}{l}0.00488^{* * *} \\
(0.000930)\end{array}$ \\
\hline Severe & $\begin{array}{l}0.126^{* * *} \\
(0.00970)\end{array}$ & $\begin{array}{c}0.0441^{* * *} \\
(0.00444)\end{array}$ & $\begin{array}{l}0.126^{* * *} \\
(0.00970)\end{array}$ & $\begin{array}{c}0.0441^{* * *} \\
(0.00444)\end{array}$ \\
\hline New prescription & $\begin{array}{c}0.110^{* * *} \\
(0.00851)\end{array}$ & $\begin{array}{c}0.0125^{* * *} \\
(0.00197)\end{array}$ & $\begin{array}{c}0.110^{* * *} \\
(0.00851)\end{array}$ & $\begin{array}{c}0.0125^{* * *} \\
(0.00197)\end{array}$ \\
\hline New diagnosis & $\begin{array}{l}0.0253^{* *} \\
(0.00918)\end{array}$ & $\begin{array}{c}-0.0121^{* * *} \\
(0.00182)\end{array}$ & $\begin{array}{c}0.0253^{* *} \\
(0.00918)\end{array}$ & $\begin{array}{c}-0.0121^{* * *} \\
(0.00182)\end{array}$ \\
\hline Medicare & $\begin{array}{l}-0.00968 \\
(0.00774)\end{array}$ & $\begin{array}{c}0.00119 \\
(0.00194)\end{array}$ & $\begin{array}{l}-0.00962 \\
(0.00774)\end{array}$ & $\begin{array}{c}0.00124 \\
(0.00194)\end{array}$ \\
\hline Medicaid & $\begin{array}{c}-0.0405^{* * *} \\
(0.00911)\end{array}$ & $\begin{array}{l}-0.00404 \\
(0.00254)\end{array}$ & $\begin{array}{c}-0.0405^{* * *} \\
(0.00911)\end{array}$ & $\begin{array}{l}-0.00406 \\
(0.00254)\end{array}$ \\
\hline $\mathrm{HMO} / \mathrm{PPO} / \mathrm{POS}$ & $\begin{array}{c}-0.0234^{* *} \\
(0.00719)\end{array}$ & $\begin{array}{r}-0.000443 \\
(0.00170)\end{array}$ & $\begin{array}{l}-0.0234^{* *} \\
(0.00719)\end{array}$ & $\begin{array}{r}-0.000426 \\
(0.00170)\end{array}$ \\
\hline Male & $\begin{array}{c}-0.00896^{* * *} \\
(0.00204)\end{array}$ & $\begin{array}{c}0.000633 \\
(0.000595)\end{array}$ & $\begin{array}{c}-0.00896^{* * *} \\
(0.00204)\end{array}$ & $\begin{array}{c}0.000633 \\
(0.000596)\end{array}$ \\
\hline Competitors' detailing & $\begin{array}{c}-0.000416 \\
(0.0202)\end{array}$ & $\begin{array}{l}0.000887 \\
(0.00556)\end{array}$ & $\begin{array}{c}-0.000407 \\
(0.0202)\end{array}$ & $\begin{array}{l}0.000893 \\
(0.00556)\end{array}$ \\
\hline After & $\begin{array}{c}0.0532^{* * *} \\
(0.00711)\end{array}$ & $\begin{array}{c}0.00594^{* * *} \\
(0.00138)\end{array}$ & $\begin{array}{c}0.0531^{* * *} \\
(0.00711)\end{array}$ & $\begin{array}{c}0.00604^{* * *} \\
(0.00138)\end{array}$ \\
\hline Senior & $\begin{array}{c}-0.0127^{* *} \\
(0.00502)\end{array}$ & $\begin{array}{l}-0.00210 \\
(0.00163)\end{array}$ & $\begin{array}{c}-0.0129^{* *} \\
(0.00504)\end{array}$ & $\begin{array}{l}-0.00205 \\
(0.00163)\end{array}$ \\
\hline Asian & $\begin{array}{l}0.00340 \\
(0.0124)\end{array}$ & $\begin{array}{c}0.00438 \\
(0.00380)\end{array}$ & $\begin{array}{c}-0.000960 \\
(0.0149)\end{array}$ & $\begin{array}{c}0.00587 \\
(0.00524)\end{array}$ \\
\hline After*Senior & $\begin{array}{c}-0.0273^{* * *} \\
(0.00450)\end{array}$ & $\begin{array}{c}-0.00501^{* *} \\
(0.00157)\end{array}$ & $\begin{array}{c}-0.0271^{* * *} \\
(0.00453)\end{array}$ & $\begin{array}{c}-0.00523^{* *} \\
(0.00159)\end{array}$ \\
\hline After*Asian & $\begin{array}{c}-0.0249^{*} \\
(0.0143)\end{array}$ & $\begin{array}{c}-0.0111^{* *} \\
(0.00411)\end{array}$ & $\begin{array}{l}-0.0223 \\
(0.0170)\end{array}$ & $\begin{array}{c}-0.0148^{* *} \\
(0.00558)\end{array}$ \\
\hline Senior Asian & & & $\begin{array}{c}0.0126 \\
(0.0196)\end{array}$ & $\begin{array}{l}-0.00432 \\
(0.00723)\end{array}$ \\
\hline After*Senior Asian & & & $\begin{array}{r}-0.00810 \\
(0.0204)\end{array}$ & $\begin{array}{c}0.0101 \\
(0.00761)\end{array}$ \\
\hline Constant & $\begin{array}{c}0.0739^{* *} \\
(0.0345)\end{array}$ & $\begin{array}{c}0.00624 \\
(0.00474)\end{array}$ & $\begin{array}{c}0.0740^{* *} \\
(0.0345)\end{array}$ & $\begin{array}{c}0.00618 \\
(0.00474)\end{array}$ \\
\hline Year*Month Dummies & Yes & Yes & Yes & Yes \\
\hline Weekday Dummies & Yes & Yes & Yes & Yes \\
\hline Observations & 227282 & 227282 & 227282 & 227282 \\
\hline Adjusted $\left(R^{2}\right)$ & 0.053 & 0.016 & 0.053 & 0.016 \\
\hline
\end{tabular}

Notes: 1. Standard errors (clustered at the physician level) in parentheses; $2{ }^{*}$ significant at $10 \% ; * *$ significant at $5 \% ; * * *$ significant at $1 \%$. 
Table 6: The Detailing by Crestor and Physicians' Prescription Volumes

\begin{tabular}{lccc}
\hline \hline & Detailed & Delay & Average competitors' detailing \\
\hline TotalRx $(1,000)$ & $2.519^{* * *}$ & $-1880.7^{* * *}$ & $1.029^{* * *}$ \\
& $(0.257)$ & $(138.7)$ & $(0.100)$ \\
TotalRx $(1,000)$ - squared & $-4.975^{* * *}$ & $4051.2^{* * *}$ & $-1.400^{* * *}$ \\
& $(0.809)$ & $(552.3)$ & $(0.412)$ \\
Constant & $0.692^{* * *}$ & $167.0^{* * *}$ & $0.0507^{* * *}$ \\
& $(0.0123)$ & $(5.463)$ & $(0.00251)$ \\
\hline$N$ & 2400 & 1842 & 2057 \\
Adjusted $R^{2}$ & 0.042 & 0.198 & 0.165 \\
\hline
\end{tabular}

Notes: 1 . Standard errors in parentheses; $2{ }^{*}$ significant at $10 \% ; * *$ significant at $5 \%$; $* *$ significant at $1 \%$.

3. "Detailed" is a binary variable that equals one if there was a Crestor detailing visit to a physician before the end of 2004 and equals zero otherwise; "Delay" is the number of days from the Crestor's approval date of Aug 13, 2003 until the first detailing visit by Crestor to a physician; and Average competitors' detailing is the competitors' detailing intensity at each physician averaged across the days from Aug 13, 2003 until the end of 2004. 
Table 7: Prescription of Crestor to Senior and Asian Patients: the Impact of Detailing

\begin{tabular}{|c|c|c|c|c|}
\hline & $\begin{array}{c}\text { Crestor (any } \\
\text { dosage) }\end{array}$ & $\begin{array}{c}\text { High-dosage } \\
\text { Crestor }\end{array}$ & $\begin{array}{c}\text { Crestor (any } \\
\text { dosage) }\end{array}$ & $\begin{array}{c}\text { High-dosage } \\
\text { Crestor }\end{array}$ \\
\hline Moderate & $\begin{array}{c}0.0479^{* * *} \\
(0.00335)\end{array}$ & $\begin{array}{c}0.00887^{* * *} \\
(0.00128)\end{array}$ & $\begin{array}{c}0.0473^{* * *} \\
(0.00341)\end{array}$ & $\begin{array}{c}0.00843^{* * *} \\
(0.00128)\end{array}$ \\
\hline Severe & $\begin{array}{l}0.153^{* * *} \\
(0.00884)\end{array}$ & $\begin{array}{c}0.0513^{* * *} \\
(0.00416)\end{array}$ & $\begin{array}{c}0.152^{* * *} \\
(0.00891)\end{array}$ & $\begin{array}{c}0.0509^{* * *} \\
(0.00414)\end{array}$ \\
\hline New prescription & $\begin{array}{c}0.0968^{* * *} \\
(0.00565)\end{array}$ & $\begin{array}{c}0.00796^{* * *} \\
(0.00139)\end{array}$ & $\begin{array}{c}0.0970^{* * *} \\
(0.00565)\end{array}$ & $\begin{array}{c}0.00835^{* * *} \\
(0.00141)\end{array}$ \\
\hline New diagnosis & $\begin{array}{c}0.0198^{* *} \\
(0.00656)\end{array}$ & $\begin{array}{c}-0.0124^{* * *} \\
(0.00146)\end{array}$ & $\begin{array}{c}0.0193^{* *} \\
(0.00653)\end{array}$ & $\begin{array}{c}-0.0126^{* * *} \\
(0.00152)\end{array}$ \\
\hline Medicare & $\begin{array}{r}-0.0205^{* * *} \\
(0.00403)\end{array}$ & $\begin{array}{r}-0.000226 \\
(0.00163)\end{array}$ & $\begin{array}{c}-0.0194^{* * *} \\
(0.00404)\end{array}$ & $\begin{array}{r}-0.000356 \\
(0.00166)\end{array}$ \\
\hline Medicaid & $\begin{array}{c}-0.0400^{* * *} \\
(0.00637)\end{array}$ & $\begin{array}{c}-0.00493^{* *} \\
(0.00242)\end{array}$ & $\begin{array}{c}-0.0399^{* * *} \\
(0.00636)\end{array}$ & $\begin{array}{l}-0.00460^{*} \\
(0.00241)\end{array}$ \\
\hline $\mathrm{HMO} / \mathrm{PPO} / \mathrm{POS}$ & $\begin{array}{c}-0.0130^{* * *} \\
(0.00345)\end{array}$ & $\begin{array}{c}0.0000564 \\
(0.00132)\end{array}$ & $\begin{array}{c}-0.0128^{* * *} \\
(0.00343)\end{array}$ & $\begin{array}{c}-0.0000953 \\
(0.00134)\end{array}$ \\
\hline Male & $\begin{array}{c}-0.00823^{* * *} \\
(0.00166)\end{array}$ & $\begin{array}{c}0.000656 \\
(0.000556)\end{array}$ & $\begin{array}{c}-0.00839^{* * *} \\
(0.00166)\end{array}$ & $\begin{array}{c}0.000615 \\
(0.000565)\end{array}$ \\
\hline Competitors' detailing & $\begin{array}{c}-0.0361^{* *} \\
(0.0169)\end{array}$ & $\begin{array}{c}-0.0151 \\
(0.00929)\end{array}$ & $\begin{array}{c}-0.0291^{*} \\
(0.0150)\end{array}$ & $\begin{array}{l}-0.00375 \\
(0.00316)\end{array}$ \\
\hline After & $\begin{array}{c}0.0304^{* * *} \\
(0.00476)\end{array}$ & $\begin{array}{c}0.00314^{*} \\
(0.00169)\end{array}$ & $\begin{array}{c}0.0298^{* * *} \\
(0.00437)\end{array}$ & $\begin{array}{c}0.00456^{* *} \\
(0.00171)\end{array}$ \\
\hline Senior & $\begin{array}{c}0.00480 \\
(0.00327)\end{array}$ & $\begin{array}{l}0.000415 \\
(0.00142)\end{array}$ & $\begin{array}{c}0.00375 \\
(0.00321)\end{array}$ & $\begin{array}{l}0.000113 \\
(0.00141)\end{array}$ \\
\hline Asian & $\begin{array}{c}0.0127 \\
(0.0111)\end{array}$ & $\begin{array}{c}0.00491 \\
(0.00374)\end{array}$ & $\begin{array}{l}0.0178^{*} \\
(0.0100)\end{array}$ & $\begin{array}{c}0.00572 \\
(0.00367)\end{array}$ \\
\hline After*Senior & $\begin{array}{r}-0.0216^{* * *} \\
(0.00316)\end{array}$ & $\begin{array}{c}-0.00434^{* * *} \\
(0.00129)\end{array}$ & $\begin{array}{r}-0.0216^{* * *} \\
(0.00314)\end{array}$ & $\begin{array}{c}-0.00405^{* *} \\
(0.00129)\end{array}$ \\
\hline After*Asian & $\begin{array}{l}-0.0185 \\
(0.0115)\end{array}$ & $\begin{array}{c}-0.0107^{* *} \\
(0.00404)\end{array}$ & $\begin{array}{c}-0.0238^{* *} \\
(0.0109)\end{array}$ & $\begin{array}{l}-0.0115^{* *} \\
(0.00405)\end{array}$ \\
\hline Constant & $\begin{array}{l}0.0274^{*} \\
(0.0152)\end{array}$ & $\begin{array}{c}0.00586 \\
(0.00515)\end{array}$ & $\begin{array}{c}-0.0344^{* *} \\
(0.0160)\end{array}$ & $\begin{array}{c}-0.00993^{* *} \\
(0.00502)\end{array}$ \\
\hline Year*Month Dummies & Yes & Yes & Yes & Yes \\
\hline Weekday Dummies & Yes & Yes & Yes & Yes \\
\hline Physician FE & Yes & Yes & No & No \\
\hline Physician*Year*Month FE & No & No & Yes & Yes \\
\hline Observations & 227282 & 227282 & 227282 & 227282 \\
\hline Adjusted $\left(R^{2}\right)$ & 0.045 & 0.015 & 0.038 & 0.011 \\
\hline
\end{tabular}

Notes: 1. Standard errors (clustered at the physician level) in parentheses; $2 .{ }^{*}$ significant at $10 \%$; ** significant at $5 \%$;*** significant at $1 \%$. 
Table 8: Heterogeneous Detailing Effect Across Physicians

\begin{tabular}{|c|c|c|c|c|}
\hline & $\begin{array}{c}\text { Crestor (any } \\
\text { dosage) }\end{array}$ & $\begin{array}{c}\text { High-dosage } \\
\text { Crestor }\end{array}$ & $\begin{array}{c}\text { Crestor (any } \\
\text { dosage) }\end{array}$ & $\begin{array}{c}\text { High-dosage } \\
\text { Crestor }\end{array}$ \\
\hline Moderate & $\begin{array}{c}0.0479^{* * *} \\
(0.00335)\end{array}$ & $\begin{array}{c}0.00887^{* * *} \\
(0.00128)\end{array}$ & $\begin{array}{c}0.0473^{* * *} \\
(0.00341)\end{array}$ & $\begin{array}{c}0.00843^{* * *} \\
(0.00128)\end{array}$ \\
\hline Severe & $\begin{array}{l}0.153^{* * *} \\
(0.00884)\end{array}$ & $\begin{array}{c}0.0513^{* * *} \\
(0.00416)\end{array}$ & $\begin{array}{l}0.152^{* * *} \\
(0.00891)\end{array}$ & $\begin{array}{c}0.0509^{* * *} \\
(0.00414)\end{array}$ \\
\hline New prescription & $\begin{array}{c}0.0968^{* * *} \\
(0.00565)\end{array}$ & $\begin{array}{c}0.00797^{* * *} \\
(0.00139)\end{array}$ & $\begin{array}{c}0.0970^{* * *} \\
(0.00565)\end{array}$ & $\begin{array}{c}0.00835^{* * *} \\
(0.00141)\end{array}$ \\
\hline New diagnosis & $\begin{array}{l}0.0197^{* *} \\
(0.00655)\end{array}$ & $\begin{array}{c}-0.0124^{* * *} \\
(0.00146)\end{array}$ & $\begin{array}{l}0.0192^{* *} \\
(0.00653)\end{array}$ & $\begin{array}{c}-0.0126^{* * *} \\
(0.00152)\end{array}$ \\
\hline Medicare & $\begin{array}{c}-0.0202^{* * *} \\
(0.00404)\end{array}$ & $\begin{array}{c}-0.000145 \\
(0.00163)\end{array}$ & $\begin{array}{c}-0.0191^{* * *} \\
(0.00405)\end{array}$ & $\begin{array}{c}-0.000282 \\
(0.00166)\end{array}$ \\
\hline Medicaid & $\begin{array}{c}-0.0400^{* * *} \\
(0.00638)\end{array}$ & $\begin{array}{c}-0.00494^{* *} \\
(0.00242)\end{array}$ & $\begin{array}{c}-0.0398^{* * *} \\
(0.00637)\end{array}$ & $\begin{array}{c}-0.00460^{*} \\
(0.00241)\end{array}$ \\
\hline $\mathrm{HMO} / \mathrm{PPO} / \mathrm{POS}$ & $\begin{array}{c}-0.0129^{* * *} \\
(0.00345)\end{array}$ & $\begin{array}{c}0.0000806 \\
(0.00132)\end{array}$ & $\begin{array}{c}-0.0127^{* * *} \\
(0.00343)\end{array}$ & $\begin{array}{c}-0.0000659 \\
(0.00134)\end{array}$ \\
\hline Male & $\begin{array}{c}-0.00824^{* * *} \\
(0.00166)\end{array}$ & $\begin{array}{c}0.000656 \\
(0.000557)\end{array}$ & $\begin{array}{c}-0.00842^{* * *} \\
(0.00166)\end{array}$ & $\begin{array}{c}0.000613 \\
(0.000566)\end{array}$ \\
\hline Competitors' detailing & $\begin{array}{c}-0.0393^{* *} \\
(0.0168)\end{array}$ & $\begin{array}{l}-0.0156^{*} \\
(0.00925)\end{array}$ & $\begin{array}{c}-0.0309^{* *} \\
(0.0150)\end{array}$ & $\begin{array}{l}-0.00383 \\
(0.00317)\end{array}$ \\
\hline After & $\begin{array}{c}0.0447^{* * *} \\
(0.00583)\end{array}$ & $\begin{array}{c}0.00532^{* *} \\
(0.00211)\end{array}$ & $\begin{array}{c}0.0412^{* * *} \\
(0.00545)\end{array}$ & $\begin{array}{c}0.00521^{* *} \\
(0.00206)\end{array}$ \\
\hline After*TotalRx & $\begin{array}{c}-0.177^{* * *} \\
(0.0323)\end{array}$ & $\begin{array}{c}-0.0271^{* *} \\
(0.0102)\end{array}$ & $\begin{array}{c}-0.142^{* * *} \\
(0.0268)\end{array}$ & $\begin{array}{l}-0.00773 \\
(0.00804)\end{array}$ \\
\hline Senior & $\begin{array}{c}0.00379 \\
(0.00329)\end{array}$ & $\begin{array}{l}0.000174 \\
(0.00143)\end{array}$ & $\begin{array}{c}0.00300 \\
(0.00322)\end{array}$ & $\begin{array}{c}-0.0000194 \\
(0.00142)\end{array}$ \\
\hline Asian & $\begin{array}{c}0.0120 \\
(0.0112)\end{array}$ & $\begin{array}{c}0.00364 \\
(0.00403)\end{array}$ & $\begin{array}{l}0.0179^{*} \\
(0.0101)\end{array}$ & $\begin{array}{c}0.00453 \\
(0.00391)\end{array}$ \\
\hline Senior Asian & $\begin{array}{c}0.00182 \\
(0.00824)\end{array}$ & $\begin{array}{c}0.00372 \\
(0.00235)\end{array}$ & $\begin{array}{c}-0.000443 \\
(0.00813)\end{array}$ & $\begin{array}{c}0.00330 \\
(0.00227)\end{array}$ \\
\hline After*Senior & $\begin{array}{c}-0.0243^{* * *} \\
(0.00361)\end{array}$ & $\begin{array}{c}-0.00462^{* *} \\
(0.00143)\end{array}$ & $\begin{array}{c}-0.0245^{* * *} \\
(0.00361)\end{array}$ & $\begin{array}{c}-0.00435^{* *} \\
(0.00144)\end{array}$ \\
\hline After*Asian & $\begin{array}{c}-0.0248^{* *} \\
(0.0125)\end{array}$ & $\begin{array}{c}-0.0119^{* *} \\
(0.00457)\end{array}$ & $\begin{array}{c}-0.0300^{* *} \\
(0.0120)\end{array}$ & $\begin{array}{c}-0.0126^{* *} \\
(0.00459)\end{array}$ \\
\hline After*Senior*TotalRx & $\begin{array}{l}0.0319^{*} \\
(0.0166)\end{array}$ & $\begin{array}{c}0.00359 \\
(0.00540)\end{array}$ & $\begin{array}{l}0.0314^{*} \\
(0.0164)\end{array}$ & $\begin{array}{c}0.00281 \\
(0.00530)\end{array}$ \\
\hline After*Asian*TotalRx & $\begin{array}{c}0.0569 \\
(0.0406)\end{array}$ & $\begin{array}{l}0.00967 \\
(0.0128)\end{array}$ & $\begin{array}{c}0.0566 \\
(0.0402)\end{array}$ & $\begin{array}{c}0.0107 \\
(0.0128)\end{array}$ \\
\hline Constant & $\begin{array}{c}0.0318^{* *} \\
(0.0151)\end{array}$ & $\begin{array}{c}0.00658 \\
(0.00514)\end{array}$ & $\begin{array}{c}-0.0338^{* *} \\
(0.0159)\end{array}$ & $\begin{array}{c}-0.00989^{* *} \\
(0.00502)\end{array}$ \\
\hline Year*Month Dummies & Yes & Yes & Yes & Yes \\
\hline Weekday Dummies & Yes & Yes & Yes & Yes \\
\hline Physician FE & Yes & Yes & No & No \\
\hline Physician*Year*Month FE & No & No & Yes & Yes \\
\hline Observations & 227282 & 227282 & 227282 & 227282 \\
\hline Adjusted $\left(R^{2}\right)$ & 0.045 & 0.015 & 0.038 & 0.011 \\
\hline
\end{tabular}

Notes: 1. Standard errors (clustered at the physician level) in parentheses; 2 . ${ }^{*}$ significant at $10 \%$;* significant at $5 \%$; *** significant at $1 \%$. 
Table 9: Prescription of Crestor to Male Patients: A Placebo Test

\begin{tabular}{|c|c|c|c|c|c|c|}
\hline & $\begin{array}{c}\text { Crestor (any } \\
\text { dosage) }\end{array}$ & $\begin{array}{l}\text { High-dosage } \\
\text { Crestor }\end{array}$ & $\begin{array}{c}\text { Crestor (any } \\
\text { dosage) }\end{array}$ & $\begin{array}{c}\text { High-dosage } \\
\text { Crestor }\end{array}$ & $\begin{array}{c}\text { Crestor (any } \\
\text { dosage) }\end{array}$ & $\begin{array}{c}\text { High-dosage } \\
\text { Crestor }\end{array}$ \\
\hline Moderate & $\begin{array}{l}0.0335^{* * *} \\
(0.00464)\end{array}$ & $\begin{array}{l}0.00488^{* * *} \\
(0.000930)\end{array}$ & $\begin{array}{c}0.0478^{* * *} \\
(0.00335)\end{array}$ & $\begin{array}{c}0.00886^{* * *} \\
(0.00128)\end{array}$ & $\begin{array}{l}0.0473^{* * *} \\
(0.00341)\end{array}$ & $\begin{array}{c}0.00842^{* * *} \\
(0.00128)\end{array}$ \\
\hline Severe & $\begin{array}{l}0.126^{* * *} \\
(0.00971)\end{array}$ & $\begin{array}{c}0.0441^{* * *} \\
(0.00444)\end{array}$ & $\begin{array}{l}0.153^{* * *} \\
(0.00884)\end{array}$ & $\begin{array}{c}0.0513^{* * *} \\
(0.00416)\end{array}$ & $\begin{array}{l}0.152^{* * *} \\
(0.00891)\end{array}$ & $\begin{array}{c}0.0509^{* * *} \\
(0.00414)\end{array}$ \\
\hline New prescription & $\begin{array}{l}0.110^{* * *} \\
(0.00851)\end{array}$ & $\begin{array}{c}0.0125^{* * *} \\
(0.00197)\end{array}$ & $\begin{array}{c}0.0968^{* * *} \\
(0.00565)\end{array}$ & $\begin{array}{c}0.00796^{* * *} \\
(0.00139)\end{array}$ & $\begin{array}{c}0.0970^{* * *} \\
(0.00565)\end{array}$ & $\begin{array}{c}0.00835^{* * *} \\
(0.00141)\end{array}$ \\
\hline New diagnosis & $\begin{array}{l}0.0253^{* *} \\
(0.00918)\end{array}$ & $\begin{array}{c}-0.0121^{* * *} \\
(0.00182)\end{array}$ & $\begin{array}{l}0.0198^{* *} \\
(0.00656)\end{array}$ & $\begin{array}{c}-0.0124^{* * *} \\
(0.00146)\end{array}$ & $\begin{array}{l}0.0193^{* *} \\
(0.00654)\end{array}$ & $\begin{array}{c}-0.0126^{* * *} \\
(0.00152)\end{array}$ \\
\hline Medicare & $\begin{array}{c}-0.0100 \\
(0.00773)\end{array}$ & $\begin{array}{c}0.00114 \\
(0.00194)\end{array}$ & $\begin{array}{c}-0.0208^{* * *} \\
(0.00404)\end{array}$ & $\begin{array}{c}-0.000290 \\
(0.00163)\end{array}$ & $\begin{array}{c}-0.0198^{* * *} \\
(0.00405)\end{array}$ & $\begin{array}{l}-0.000417 \\
(0.00166)\end{array}$ \\
\hline Medicaid & $\begin{array}{c}-0.0408^{* * *} \\
(0.00912)\end{array}$ & $\begin{array}{l}-0.00410 \\
(0.00254)\end{array}$ & $\begin{array}{c}-0.0404^{* * *} \\
(0.00638)\end{array}$ & $\begin{array}{c}-0.00499^{* *} \\
(0.00242)\end{array}$ & $\begin{array}{c}-0.0402^{* * *} \\
(0.00636)\end{array}$ & $\begin{array}{c}-0.00466^{*} \\
(0.00241)\end{array}$ \\
\hline $\mathrm{HMO} / \mathrm{PPO} / \mathrm{POS}$ & $\begin{array}{c}-0.0235^{* *} \\
(0.00720)\end{array}$ & $\begin{array}{r}-0.000460 \\
(0.00170)\end{array}$ & $\begin{array}{c}-0.0132^{* * *} \\
(0.00346)\end{array}$ & $\begin{array}{c}0.0000267 \\
(0.00132)\end{array}$ & $\begin{array}{c}-0.0130^{* * *} \\
(0.00344)\end{array}$ & $\begin{array}{c}-0.000124 \\
(0.00134)\end{array}$ \\
\hline Male & $\begin{array}{c}-0.00944^{* *} \\
(0.00295)\end{array}$ & $\begin{array}{l}-0.000716 \\
(0.000797)\end{array}$ & $\begin{array}{c}-0.00882^{* * *} \\
(0.00255)\end{array}$ & $\begin{array}{l}-0.000704 \\
(0.000817)\end{array}$ & $\begin{array}{c}-0.00932^{* * *} \\
(0.00253)\end{array}$ & $\begin{array}{l}-0.000424 \\
(0.000800)\end{array}$ \\
\hline Competitors' detailing & $\begin{array}{c}-0.000490 \\
(0.0202)\end{array}$ & $\begin{array}{l}0.000884 \\
(0.00557)\end{array}$ & $\begin{array}{c}-0.0357^{* *} \\
(0.0170)\end{array}$ & $\begin{array}{c}-0.0151 \\
(0.00930)\end{array}$ & $\begin{array}{c}-0.0288^{*} \\
(0.0150)\end{array}$ & $\begin{array}{l}-0.00379 \\
(0.00316)\end{array}$ \\
\hline After & $\begin{array}{c}0.0401^{* * *} \\
(0.00626)\end{array}$ & $\begin{array}{l}0.00262^{*} \\
(0.00138)\end{array}$ & $\begin{array}{c}0.0199^{* * *} \\
(0.00464)\end{array}$ & $\begin{array}{c}0.0000900 \\
(0.00187)\end{array}$ & $\begin{array}{c}0.0187^{* * *} \\
(0.00436)\end{array}$ & $\begin{array}{c}0.00178 \\
(0.00196)\end{array}$ \\
\hline Senior & $\begin{array}{c}-0.0361^{* * *} \\
(0.00445)\end{array}$ & $\begin{array}{c}-0.00641^{* * *} \\
(0.00136)\end{array}$ & $\begin{array}{c}-0.0138^{* * *} \\
(0.00265)\end{array}$ & $\begin{array}{c}-0.00332^{* *} \\
(0.00104)\end{array}$ & $\begin{array}{c}-0.0148^{* * *} \\
(0.00264)\end{array}$ & $\begin{array}{c}-0.00337^{* *} \\
(0.00105)\end{array}$ \\
\hline Asian & $\begin{array}{c}-0.0186^{* *} \\
(0.00814)\end{array}$ & $\begin{array}{c}-0.00540^{* * *} \\
(0.00148)\end{array}$ & $\begin{array}{l}-0.00348 \\
(0.00507)\end{array}$ & $\begin{array}{c}-0.00450^{* *} \\
(0.00150)\end{array}$ & $\begin{array}{l}-0.00301 \\
(0.00504)\end{array}$ & $\begin{array}{c}-0.00435^{* *} \\
(0.00149)\end{array}$ \\
\hline After*Male & $\begin{array}{l}0.000577 \\
(0.00375)\end{array}$ & $\begin{array}{c}0.00156 \\
(0.00106)\end{array}$ & $\begin{array}{l}0.000686 \\
(0.00312)\end{array}$ & $\begin{array}{c}0.00156 \\
(0.00104)\end{array}$ & $\begin{array}{c}0.00107 \\
(0.00310)\end{array}$ & $\begin{array}{c}0.00119 \\
(0.00103)\end{array}$ \\
\hline Constant & $\begin{array}{l}0.0858^{* *} \\
(0.0350)\end{array}$ & $\begin{array}{l}0.00928^{*} \\
(0.00480)\end{array}$ & $\begin{array}{l}0.0369^{* *} \\
(0.0150)\end{array}$ & $\begin{array}{l}0.00862^{*} \\
(0.00518)\end{array}$ & $\begin{array}{l}-0.0246 \\
(0.0158) \\
\end{array}$ & $\begin{array}{l}-0.00745 \\
(0.00501)\end{array}$ \\
\hline Year*Month Dummies & Yes & Yes & Yes & Yes & Yes & Yes \\
\hline Weekday Dummies & Yes & Yes & Yes & Yes & Yes & Yes \\
\hline Physician FE & No & No & Yes & Yes & No & No \\
\hline Physician*Year*Month FE & No & No & No & No & Yes & Yes \\
\hline Observations & 227282 & 227282 & 227282 & 227282 & 227282 & 227282 \\
\hline Adjusted $\left(R^{2}\right)$ & 0.053 & 0.016 & 0.044 & 0.015 & 0.038 & 0.011 \\
\hline
\end{tabular}

Notes: 1. Standard errors (clustered at the physician level) in parentheses; $2{ }^{*}$ significant at $10 \%$; $* *$ significant at $5 \%$; *** significant at $1 \%$. 
Table 10: Prescription of Crestor to Hispanic Patients: A Placebo Test

\begin{tabular}{|c|c|c|c|c|c|c|}
\hline & $\begin{array}{c}\text { Crestor (any } \\
\text { dosage) }\end{array}$ & $\begin{array}{c}\text { High-dosage } \\
\text { Crestor }\end{array}$ & $\begin{array}{c}\text { Crestor (any } \\
\text { dosage) }\end{array}$ & $\begin{array}{l}\text { High-dosage } \\
\text { Crestor }\end{array}$ & $\begin{array}{c}\text { Crestor (any } \\
\text { dosage) }\end{array}$ & $\begin{array}{c}\text { High-dosage } \\
\text { Crestor }\end{array}$ \\
\hline Moderate & $\begin{array}{c}0.0335^{* * *} \\
(0.00465)\end{array}$ & $\begin{array}{l}0.00489^{* * *} \\
(0.000932)\end{array}$ & $\begin{array}{c}0.0478^{* * *} \\
(0.00335)\end{array}$ & $\begin{array}{c}0.00886^{* * *} \\
(0.00128)\end{array}$ & $\begin{array}{c}0.0473^{* * *} \\
(0.00341)\end{array}$ & $\begin{array}{c}0.00842^{* * *} \\
(0.00128)\end{array}$ \\
\hline Severe & $\begin{array}{l}0.126^{* * *} \\
(0.00971)\end{array}$ & $\begin{array}{c}0.0441^{* * *} \\
(0.00444)\end{array}$ & $\begin{array}{l}0.153^{* * *} \\
(0.00884)\end{array}$ & $\begin{array}{c}0.0513^{* * *} \\
(0.00416)\end{array}$ & $\begin{array}{l}0.152^{* * *} \\
(0.00891)\end{array}$ & $\begin{array}{l}0.0509^{* * *} \\
(0.00414)\end{array}$ \\
\hline New prescription & $\begin{array}{l}0.110^{* * *} \\
(0.00851)\end{array}$ & $\begin{array}{c}0.0125^{* * *} \\
(0.00197)\end{array}$ & $\begin{array}{c}0.0968^{* * *} \\
(0.00565)\end{array}$ & $\begin{array}{c}0.00796^{* * *} \\
(0.00139)\end{array}$ & $\begin{array}{c}0.0970^{* * *} \\
(0.00565)\end{array}$ & $\begin{array}{c}0.00835^{* * *} \\
(0.00141)\end{array}$ \\
\hline New diagnosis & $\begin{array}{l}0.0254^{* *} \\
(0.00919)\end{array}$ & $\begin{array}{c}-0.0120^{* * *} \\
(0.00182)\end{array}$ & $\begin{array}{l}0.0198^{* *} \\
(0.00656)\end{array}$ & $\begin{array}{c}-0.0124^{* * *} \\
(0.00146)\end{array}$ & $\begin{array}{l}0.0193^{* *} \\
(0.00653)\end{array}$ & $\begin{array}{c}-0.0126^{* * *} \\
(0.00152)\end{array}$ \\
\hline Medicare & $\begin{array}{c}-0.0107 \\
(0.00767)\end{array}$ & $\begin{array}{c}0.00103 \\
(0.00191)\end{array}$ & $\begin{array}{c}-0.0208^{* * *} \\
(0.00404)\end{array}$ & $\begin{array}{r}-0.000295 \\
(0.00163)\end{array}$ & $\begin{array}{c}-0.0198^{* * *} \\
(0.00405)\end{array}$ & $\begin{array}{r}-0.000422 \\
(0.00166)\end{array}$ \\
\hline Medicaid & $\begin{array}{c}-0.0400^{* * *} \\
(0.00914)\end{array}$ & $\begin{array}{l}-0.00398 \\
(0.00253)\end{array}$ & $\begin{array}{c}-0.0404^{* * *} \\
(0.00638)\end{array}$ & $\begin{array}{c}-0.00499^{* *} \\
(0.00242)\end{array}$ & $\begin{array}{c}-0.0402^{* * *} \\
(0.00636)\end{array}$ & $\begin{array}{c}-0.00466^{*} \\
(0.00241)\end{array}$ \\
\hline HMO/PPO/POS & $\begin{array}{c}-0.0233^{* *} \\
(0.00719)\end{array}$ & $\begin{array}{c}-0.000430 \\
(0.00170)\end{array}$ & $\begin{array}{c}-0.0132^{* * *} \\
(0.00346)\end{array}$ & $\begin{array}{c}0.0000282 \\
(0.00132)\end{array}$ & $\begin{array}{c}-0.0130^{* * *} \\
(0.00343)\end{array}$ & $\begin{array}{l}-0.000125 \\
(0.00134)\end{array}$ \\
\hline Hispanic & $\begin{array}{l}-0.00534 \\
(0.00776)\end{array}$ & $\begin{array}{r}-0.000457 \\
(0.00201)\end{array}$ & $\begin{array}{l}-0.00144 \\
(0.00640)\end{array}$ & $\begin{array}{l}-0.00184 \\
(0.00294)\end{array}$ & $\begin{array}{l}-0.00418 \\
(0.00594)\end{array}$ & $\begin{array}{l}-0.00304 \\
(0.00297)\end{array}$ \\
\hline Male & $\begin{array}{c}-0.00903^{* * *} \\
(0.00203)\end{array}$ & $\begin{array}{c}0.000623 \\
(0.000593)\end{array}$ & $\begin{array}{c}-0.00822^{* * *} \\
(0.00166)\end{array}$ & $\begin{array}{c}0.000655 \\
(0.000556)\end{array}$ & $\begin{array}{c}-0.00839^{* * *} \\
(0.00166)\end{array}$ & $\begin{array}{c}0.000613 \\
(0.000565)\end{array}$ \\
\hline Competitors' detailing & $\begin{array}{l}0.00125 \\
(0.0201)\end{array}$ & $\begin{array}{c}0.00115 \\
(0.00560)\end{array}$ & $\begin{array}{c}-0.0358^{* *} \\
(0.0170)\end{array}$ & $\begin{array}{c}-0.0151 \\
(0.00931)\end{array}$ & $\begin{array}{l}-0.0290^{*} \\
(0.0151)\end{array}$ & $\begin{array}{l}-0.00386 \\
(0.00315)\end{array}$ \\
\hline After & $\begin{array}{c}0.0407^{* * *} \\
(0.00643)\end{array}$ & $\begin{array}{c}0.00352^{* *} \\
(0.00131)\end{array}$ & $\begin{array}{c}0.0201^{* * *} \\
(0.00443)\end{array}$ & $\begin{array}{l}0.000844 \\
(0.00167)\end{array}$ & $\begin{array}{c}0.0190^{* * *} \\
(0.00403)\end{array}$ & $\begin{array}{c}0.00226 \\
(0.00173)\end{array}$ \\
\hline Senior & $\begin{array}{c}-0.0355^{* * *} \\
(0.00433)\end{array}$ & $\begin{array}{c}-0.00631^{* * *} \\
(0.00133)\end{array}$ & $\begin{array}{c}-0.0138^{* * *} \\
(0.00265)\end{array}$ & $\begin{array}{c}-0.00332^{* *} \\
(0.00104)\end{array}$ & $\begin{array}{c}-0.0148^{* * *} \\
(0.00264)\end{array}$ & $\begin{array}{c}-0.00337^{* *} \\
(0.00105)\end{array}$ \\
\hline Asian & $\begin{array}{l}-0.0194^{* *} \\
(0.00817)\end{array}$ & $\begin{array}{c}-0.00552^{* * *} \\
(0.00150)\end{array}$ & $\begin{array}{l}-0.00331 \\
(0.00509)\end{array}$ & $\begin{array}{c}-0.00452^{* *} \\
(0.00149)\end{array}$ & $\begin{array}{l}-0.00277 \\
(0.00506)\end{array}$ & $\begin{array}{c}-0.00437^{* *} \\
(0.00148)\end{array}$ \\
\hline After*Hispanic & $\begin{array}{c}-0.00800 \\
(0.0121)\end{array}$ & $\begin{array}{l}-0.00160 \\
(0.00287)\end{array}$ & $\begin{array}{c}0.00307 \\
(0.00746)\end{array}$ & $\begin{array}{c}0.00183 \\
(0.00302)\end{array}$ & $\begin{array}{c}0.00659 \\
(0.00706)\end{array}$ & $\begin{array}{c}0.00326 \\
(0.00307)\end{array}$ \\
\hline Constant & $\begin{array}{c}0.0855^{* *} \\
(0.0346)\end{array}$ & $\begin{array}{l}0.00851^{*} \\
(0.00474)\end{array}$ & $\begin{array}{c}0.0366^{* *} \\
(0.0151)\end{array}$ & $\begin{array}{c}0.00795 \\
(0.00514)\end{array}$ & $\begin{array}{l}-0.0249 \\
(0.0159)\end{array}$ & $\begin{array}{l}-0.00786 \\
(0.00496)\end{array}$ \\
\hline Year*Month Dummies & Yes & Yes & Yes & Yes & Yes & Yes \\
\hline Weekday Dummies & Yes & Yes & Yes & Yes & Yes & Yes \\
\hline Physician FE & No & No & Yes & Yes & No & No \\
\hline Physician*Year*Month FE & No & No & No & No & Yes & Yes \\
\hline Observations & 227282 & 227282 & 227282 & 227282 & 227282 & 227282 \\
\hline Adjusted $\left(R^{2}\right)$ & 0.053 & 0.016 & 0.044 & 0.015 & 0.037 & 0.011 \\
\hline
\end{tabular}

Notes: 1. Standard errors (clustered at the physician level) in parentheses; $2 .{ }^{*}$ significant at $10 \%$; ${ }^{* *}$ significant at $5 \%$; $* * *$ significant at $1 \%$. 